EPiC Series in Engineering
Volume 3, 2018, Pages 351-355
HIC 2018. 13th International
Conference on Hydroinformatics

\title{
From CCTV data to strategic planning: deterioration modelling for large sewer networks in Germany and Colombia
}

\author{
Nicolas Caradot $^{1}$, Nathalie Hernandez ${ }^{2}$, Hauke Sonnenberg ${ }^{1}$, \\ Andres Torres ${ }^{2}$ and Pascale Rouault ${ }^{1}$ \\ ${ }^{1}$ Kompetenzzentrum Wasser Berlin gGmbH, Cicerostr. 24, 10709 Berlin, Germany \\ ${ }^{2}$ Pontificia Universidad Javeriana, Faculty of Engineering, Bogotá D.C., Colombia \\ nicolas.caradot@kompetenz-wasser.de
}

\begin{abstract}
Most cities are facing an aging sewer infrastructure in extensive and emerging need of repair, rehabilitation or renewal. Deterioration modelling can be a valued data mining tool to tackle this issue by supporting utilities in defining strategic investment planning. This study aims to demonstrate the benefits of deterioration modelling using sewer CCTV inspection data and GIS characteristics (material, age, depth, width, traffic load, etc.) of two different cities: Braunschweig in Germany and Bogota in Colombia. A probabilistic Markov-based model has been applied to identify and exploit relationships between sewer condition and characteristics in the extensive datasets of the two cities. The quality of prediction of the model has been evaluated by analyzing the deviation between model observations and model predictions. Results show relatively low deviations $(<15 \%)$ indicating a satisfying model performance in both cities and underlining the relevance of deterioration models to simulate the condition of sewer networks and to support strategic asset management.
\end{abstract}

\section{Introduction}

The wastewater infrastructures including collection pipes and treatment facilities represent an enormous investment in physical assets. The replacement value of these assets amounts to millions of euros for every major city but also small municipalities [1]. During the last 30 years, most municipalities have invested in sewer system expansion to meet growth and treatment plant upgrade but a relatively small proportion of the budget has been allocated to sewer rehabilitation [2]. As a result, most cities face an aging infrastructure in extensive and emerging need of repair, rehabilitation or renewal. 
The ASCE estimated the required capital investment to maintain and upgrade water infrastructure in the USA as $\$ 91$ billion. However, only $\$ 36$ billion of this $\$ 91$ billion needed was funded, leaving a capital funding gap of nearly $\$ 55$ billion. In Germany, a national study estimates that about $17 \%$ of the sewers have severe defects and should be rehabilitated immediately or in the short term [3]. Over the last years, the annual investment for sewer rehabilitation was about 4 billion $€$ whereas capital need is estimated to more than 7 billion $€$, indicating a capital deficit of at least 3 billion $€$ [4].

Deterioration models have been developed to forecast the evolution of the system according to its current and past condition. They can be used (i) for the scheduling of inspection programs (i.e. the detection of sewers in critical condition) and the planning of rehabilitation budgets (i.e. comparison of different sewer rehabilitation scenarios and the evaluation of necessary investment rates). Several modelling approaches are now available $[5,6,7]$ but not commonly used by sewer operators to support strategies. Indeed, most of these models still fail to show that they can adequately forecast the evolution of the network condition [8].

This paper aims at demonstrating the performance of deterioration modelling to predict the future deterioration of the network, i.e. the evolution of the condition distribution over time, using the extensive CCTV datasets of two cities in very different contexts: Braunschweig in Germany and Bogota in Colombia.

\section{Material and methods}

The statistical Markov chain model GompitZ [9] has been calibrated and validated using CCTV and GIS data of both case studies. For each sewer, the inspected sewer condition has been compared with the predicted condition at the year of inspection. Model performance has been assessed by analysing the deviation between model predictions and observations.

For the city of Braunschweig (250.000 inhabitants), all pipes have been inspected at least once. After data clean-up, 37.506 consistent CCTV inspections (representing $1.476 \mathrm{~km}$ ) were linked to 23.958 sewer pipes. The structural condition of the inspected pipes has been evaluated using the French classification methodology RERAU [10]. A structural condition class is assigned to each sewer segment (from manhole to manhole) on a four-grade scale ( 1 to 4, 4 being the worst condition meaning that immediate rehabilitation is needed). The influence of sewer characteristics on sewer condition is represented in Figure 1. It shows that the variables "construction year", "material", "type of effluent (sewerage)" and "depth" have a clear influence on sewer condition.

The database of Bogota (6,7 billion inhabitants) contains after data clean-up 5.076 consistent CCTV inspections (representing $245 \mathrm{~km}$ ) linked to 5.031 sewer pipes. The structural condition of the inspected pipes has been evaluated using the local sewer assessment methodology NS - 058 [11]. It attributes a score from 1 to 5 to each inspected pipe, 5 being the being the worst condition. Figure 2 shows the influence of sewer characteristics on sewer condition: "construction year", "material", "type of effluent (sewerage)", "depth", "diameter" and "length" seem to be the variables that influence most sewer condition. Note that the original scores 3 and 4 have been grouped in order to have only 4 condition classes and allow comparison with Braunschweig.

\section{Results and conclusion}

Figure 3 shows model results for both case studies. Figure 3 [top] shows the inspected condition of the entire dataset (5.076 pipes in Bogota and 37.506 pipes in Braunschweig). Figure 3 [middle] shows the predicted condition of the same dataset. Figure 3 [bottom] shows the deviation between the predicted and inspected proportions of sewers in bad condition 4 (red bars). 

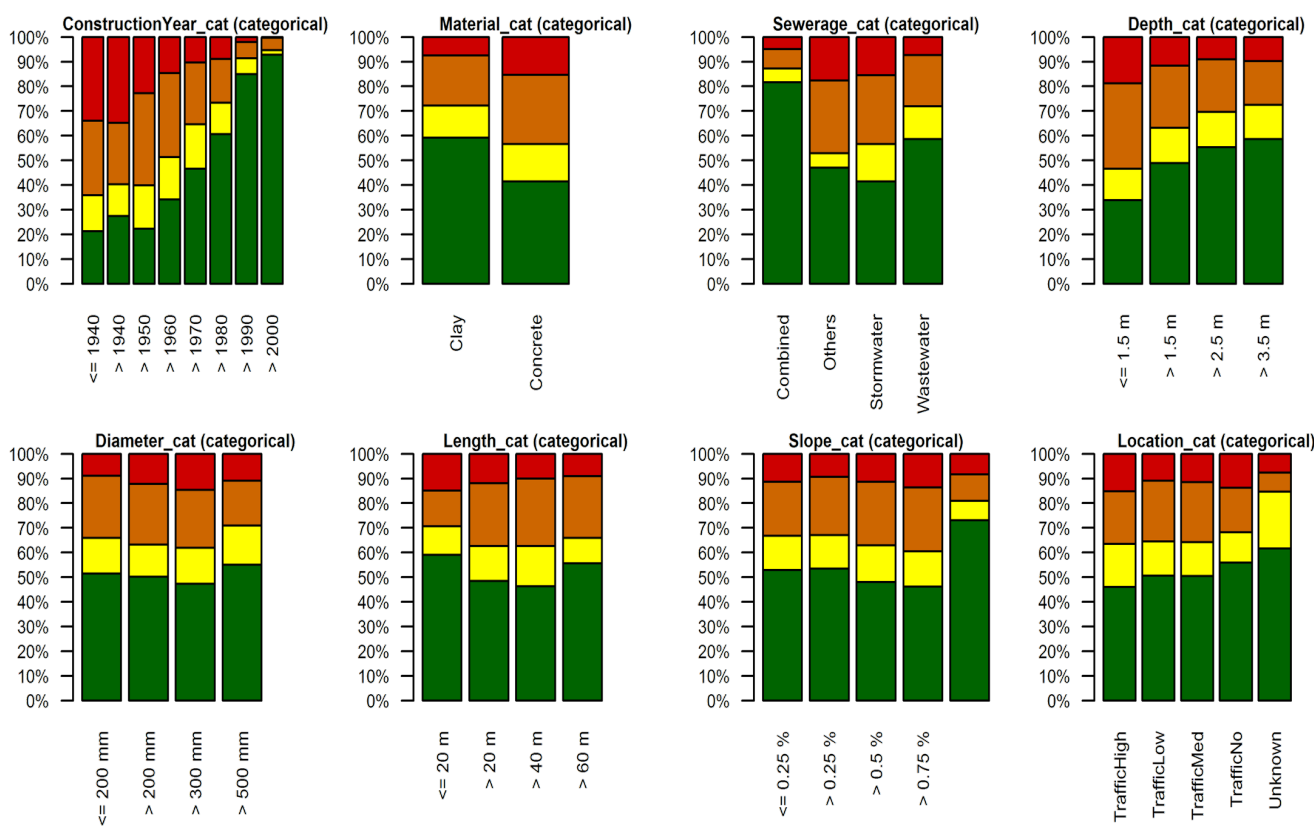

Figure 1 Sewer characteristics in Braunschweig used as variables in the statistical model. The condition ranges from 1 (green) to 4 (red), with 4 being the worst condition. Please note that this graph shows the condition distribution of the set of inspected sewers but not of the sewer system itself: some sewers have been inspected several times
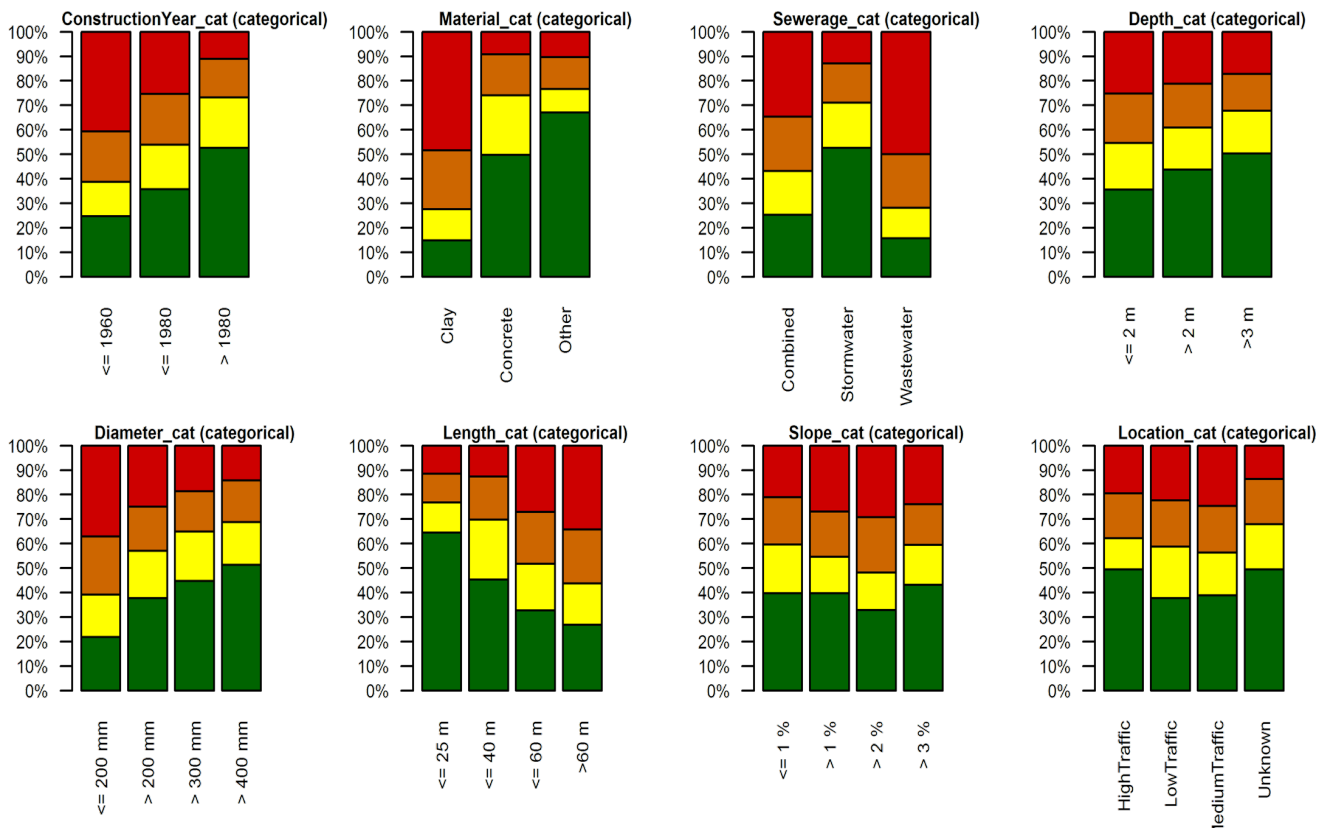

Figure 2 Sewer characteristics in Bogota used as variables in the statistical model. The condition ranges from 1 (green) to 4 (red), with 4 being the worst condition. Please note that this graph shows the condition distribution of the set of inspected sewers but not of the sewer system itself: some sewers have been inspected several times 
For each age period, the deviations are relatively low $(<15 \%)$ indicating a satisfying model performance and underlining the relevance of deterioration models to simulate the condition of sewer networks. Deviations are slightly positive for the last age period (70-80 years) due to left truncated inspection data: already replaced pipes have not necessarily been inspected. This leads to a selective survival bias and to an over representation of sewer in good condition (survivors).

Ongoing works are focusing on the assessment of model performance at the pipe level for investment prioritization and pipe rehabilitation programs as well as the assessment of uncertainties in model outputs [12]. Aim is to evaluate the required investment confidence interval to achieve a desired network condition.
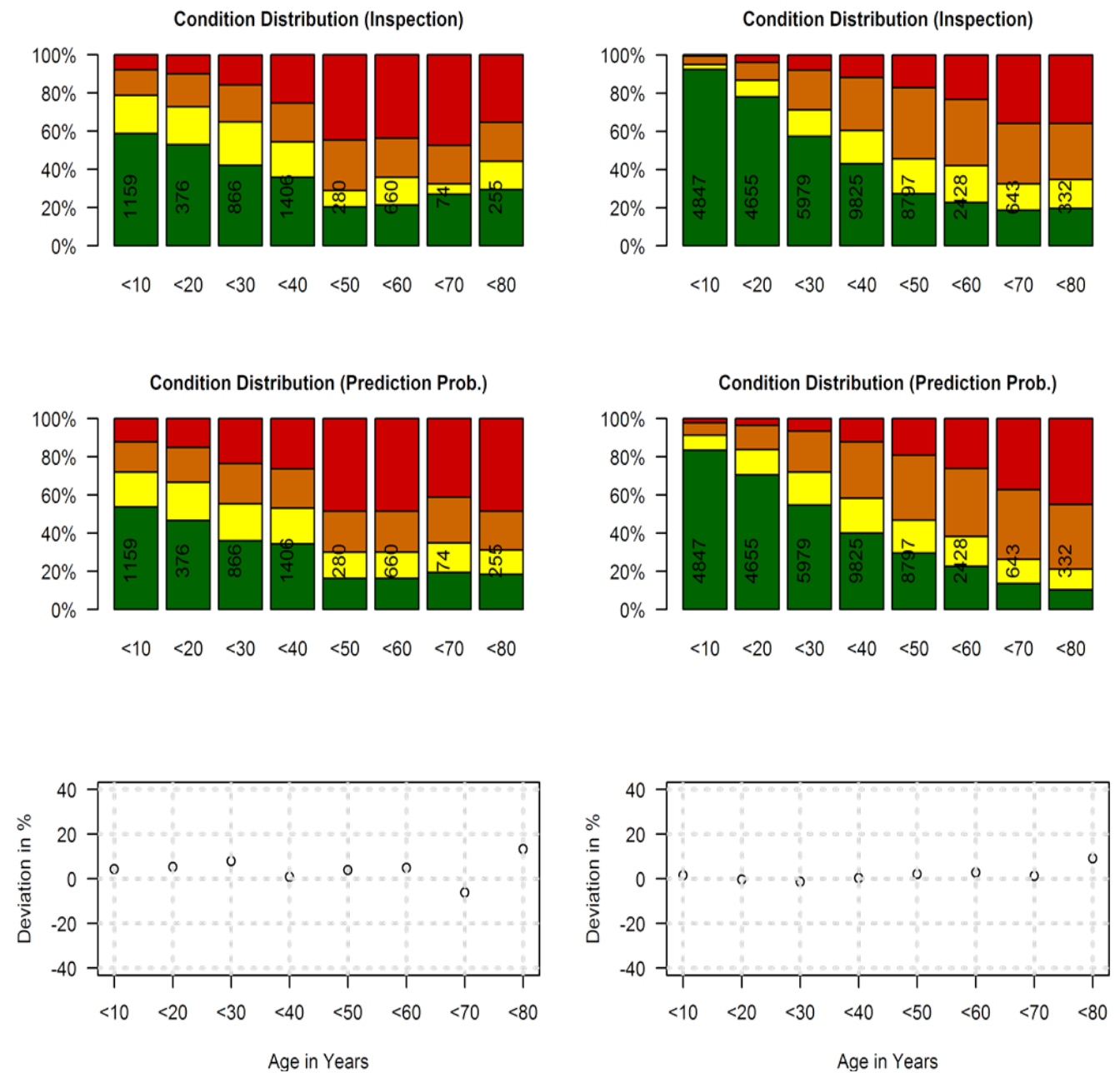

Figure 3 Inspected [top] and predicted [middle] condition distributions of the inspected sewers in the cities of Bogota (left) and Braunschweig (right). Bottom graphs show the deviations between the predicted and inspected proportions of sewers in bad condition 4 


\section{Acknowledgement}

Part of this research has been sponsored by Veolia in the frame of the project SEMA (2012-2015). The authors would like to thank all colleagues involved in the project, especially Michael Timm from SE|BS for the preparation of CCTV and sewer data in Braunschweig. The authors would like also to thank EAB for supplying the database information of Bogota. This research is supported by the program PROCOL, bilateral convention between DAAD in Germany and COLCIENCAS in Colombia, including funding from the German Federal Ministry of Education and Research (BMBF).

\section{References}

[1] IPK, Impulse Pro Kanalbau (2014), Forderungskatalog 2014: Forderungskatalog für funktionsfähige öffentliche und private Abwasseranlage

[2] American Water Works Association (2012), Buried No Longer: Confronting America's Water Infrastructure Challenge. Report, 37p

[3] DWA (2009), Zustand der Kanalisation in Deutschland, Ergebnisse der DWA-Umfrage 2009. Hennef, Deutsche Vereinigung für Wasserwirtschaft, Abwasser und Abfall e.V.

[4] Branchenbild der deutschen Wasserwirtschaft (2011), Report 2011

[5] Kley, G., Caradot, N. (2013) Review of sewer deterioration models. KWB project SEMA, Report 1.2, 43p, available on KWB website

[6] Sousa, V., Matos, J.P., Matias, N. (2014) Evaluation of artificial intelligence tool performance and uncertainty for predicting sewer structural condition. Automation in Construction, Volume 44, August 2014, 84-91

[7] Vitorino, D., Coelho, S.T., Santos, P., Sheets, S., Jurkovac, B., Amado, C. (2014), A Random Forest Algorithm Applied to Condition-based Wastewater Deterioration Modeling and Forecasting, Procedia Engineering, Volume 89, 2014, 401-410, 16th Water Distribution System Analysis Conference, WDSA 2014

[8] Ana, E. V., Bauwens, W. (2010), Modeling the structural deterioration of urban drainage pipes: The state-of-the-art in statistical methods. Urban Water Journal, 7 (1), 47-59

[9] Le Gat, Y. (2008), Modeling the deterioration process of drainage pipelines. Urban Water Journal, 5, 97-106

[10] Ahmadi, M., Cherqui, F., De Massiac, J.C, Werey, C., Lagoutte, S. \& Le Gauffre, P. (2014), Condition grading for dysfunction indicators in sewer asset management. Structure and Infrastructure Engineering: Maintenance, Management, Life-Cycle Design and Performance. 10 (3), 346-358

[11] Empresa de Acueducto y Alcantarillado de Bogotá EAAB (2001), NS - 058. Aspectos Técnicos para inspección y mantenimiento de redes y estructuras de alcantarillado. Bogotá, Colombia, EAAB-E.S.P.

[12] Caradot N., Rouault P., Clemens F., Cherqui F., 2017, Evaluation of uncertainties in sewer condition assessment. Structure and Infrastructure Engineering: Maintenance, Management, Life-Cycle Design and Performance, Published online: 02 Aug 2017 